\title{
Outcomes of biliopancreatic EUS in patients with surgically altered upper gastrointestinal anatomy: a multicenter study
}

\section{다 $(-) \odot$}

\author{
Authors \\ Lorenzo Brozzi ${ }^{1}$, Maria Chiara Petrone ${ }^{2}$, Jan-Werner Poley ${ }^{3}$, Silvia Carrara ${ }^{4}$, Luca Barresi ${ }^{5}$, Carlo Fabbri ${ }^{6}$, Mihai \\ Rimbas $^{7}$, Claudio De Angelis ${ }^{8}$, Paolo Giorgio Arcidiacono², Marianna Signoretti ${ }^{3,6}$, Laura Lamonaca ${ }^{4}$, Ilenia \\ Barbuscio $^{5}$, Cecilia Binda ${ }^{6}$, Andrada Gheorghe ${ }^{7}$, Stefano Rizza ${ }^{8}$, Armando Gabbrielli ${ }^{1}$, Stefano Francesco Crinò ${ }^{1}$
}

Institutions

1 Gastroenterology and Digestive Endoscopy Unit, The Pancreas Institute, G.B. Rossi University Hospital, Verona, Italy

2 PancreatoBiliary Endoscopy and EUS Division, Pancreas Translational and Clinical Research Center, San Raffaele Scientific Institute IRCCS, Milan, Italy

3 Department of Gastroenterology and Hepatology, Erasmus MC, University Medical Centre, Rotterdam, the Netherlands

4 Humanitas Clinical and Research Center- IRCCSDigestive Endoscopy Unit, Division of Gastroenterology, Rozzano (Milan), Italy

5 Endoscopy Service, Department of Diagnostic and Therapeutic Services, IRCCS-ISMETT (Mediterranean Institute for Transplantation and Highly Specialized Therapies), Palermo, Italy

6 Unit of Gastroenterology and Digestive Endoscopy, Forli-Cesena Hospital, AUSL Romagna, Forli-Cesena, Italy

7 Gastroenterology Department, Colentina Clinical Hospital, Carol Davila University of Medicine, Bucharest, Romania

8 Gastroenterology and Digestive Endoscopy Unit, Città della Salute e della Scienza di Torino, Turin, Italy

submitted 26.1.2020

accepted after revision 30.3.2020

Bibliography

DOI https://doi.org/10.1055/a-1161-8713 |

Endoscopy International Open 2020; 08: E869-E876

(c) Georg Thieme Verlag KG Stuttgart · New York

elSSN 2196-9736

Corresponding author

Stefano Francesco Crinò, MD, Gastroenterology and

Digestive Endoscopy Unit, G. B. Rossi University Hospital,

P.le L.A. Scuro 10, Verona - 37134, Italy

Fax: +00390458124898

stefanocrino@hotmail.com

\section{ABSTRACT}

Background and study aims Little is known about outcomes of biliopancreatic endosonography (EUS) in patients with surgically altered upper gastrointestinal (gastrointestinal) anatomy. We aimed to assess the rate of procedural success and EUS-related adverse events (AEs), according to post-surgical anatomies.

Patients and methods Retrospective study including patients with post-surgical altered upper gastrointestinal anatomy who underwent EUS for evaluation of the biliopancreatic region between January 2008 and June 2018 at eight European centers.

Results Of 242 patients ( 162 males, mean age $66.4 \pm 12.5$ ), 86 had (35.5\%) Billroth II, 77 (31.8\%) pancreaticoduodenectomy, 23 (9.5\%) Billroth I, 19 (7.9\%) distal esophagectomy, $15(6.2 \%)$ total gastrectomy, 14 (5.8\%) sleeve gastrectomy, and eight (3.3\%) Roux-en-Y. Sleeve gastrectomy, Billroth I, and pancreaticoduodenectomy were associated with high rates of success $(100 \%, 95.7 \%$, and $92.2 \%$, respectively). Visualization of the head of the pancreas was significantly impacted by total gastrectomy, Billroth II, and Roux-en-Y (success rates $6.7 \%, 53.7 \%$, and $57.1 \%$, respectively). Examination of the pancreatic body and tail was impaired in esophagectomy and total gastrectomy $(82.4 \%$ and $71.4 \%$, respectively). Technical success and diagnostic accuracy of EUS-guided tissue acquisition (EUS-TA) was $78.2 \%$ and $71.3 \%(95 \% \mathrm{Cl}, 60.6-80.5)$, respectively. Four (1.6\%) AEs were observed: one mucosal tearing in a Billroth Il patient, one cardiac arrest in a distal esophagectomy patient, one bleed after EUS-TA in a Billroth I patient, and one acute pancreatitis after EUS-TA in a sleeve gastrectomy patient.

Conclusions The yield of bilio-pancreatic EUS is dependent on lesion location and surgery type. Before considering EUS in these patients, one must carefully consider whether the lesion may be approachable by EUS. 


\section{Introduction}

Endoscopic Ultrasound (EUS) is an extremely valuable procedure for detection, staging, and cytohistological characterization of biliopancreatic diseases. However, the quality of endosonographic image resolution of the pancreas and potential for performing fine-needle aspiration or biopsy under EUS-guidance are strictly dependent on the proximity of the transducer to the gastrointestinal lumen and to the biliopancreatic region.

An altered status of upper gastrointestinal anatomy due to previous surgery may represent a hurdle for pancreatic examination and tissue acquisition (TA), due to the theoretical difficulty in achieving an adequate scan of the pancreas or the distal bile duct. It is widely accepted that performing endoscopic retrograde cholangiopancreatography (ERCP) on surgically altered anatomy is technically difficult and associated with a higher rate of failure and complications when compared to standard procedures, especially in the case of Billroth II, Rouxen-Y and post-Whipple anatomy [1-3]. In addition, little is known about the outcomes of EUS in this subset of patients and only a few case series and one retrospective single-center study have been published so far [4-9]. Moreover, in recent decades, the types of surgical interventions have gradually changed. In particular, fewer an fewer Billroth II procedures are being performed while the number of bariatric surgeries has grown.

Therefore, we performed a retrospective multicenter study in patients with altered upper gastrointestinal anatomy, with the aim of investigating the performance of EUS in satisfactory visualization of the biliopancreatic region and assessing the rate of EUS-related adverse events (AEs) and evaluating the diagnostic accuracy of EUS-TA for solid pancreatic or distal bile duct lesions.

\section{Patients and methods}

\section{Study population and data collection}

This was a retrospective multicenter study involving eight European centers. The study was approved by the IRB/Ethics Committee at each center (Prog. N.1921CESC, 2018.09.19).

All adult patients with a previous upper gastrointestinal surgical procedure (e.g., esophagectomy, total gastrectomy with esophagojejunostomy, sleeve gastrectomy, Billroth I, Billroth II, Roux-en-Y gastric bypass with gastrojejunostomy, Whipple pancreaticoduodenectomy, pylorus-preserving pancreaticoduodenectomy) who underwent EUS between January 2008 and June 2018 were identified from the hospitals' electronic databases of endoscopic reports and the charts of identified patients were carefully reviewed.

Cases of surgery that did not significantly alter the upper gastrointestinal anatomy (e.g., Roux-en-Y bilio-digestive anastomosis or gastric banding) or EUS performed for evaluation of other than bilio-pancreatic region were excluded. For patients with more than one procedure performed during the inclusion period, only the first attempt was included, whereas subsequent procedures were excluded.
Data about the demographics, previous surgery (indication, type of surgery and anastomosis, and year of execution), echoendoscope used (radial or linear ultrasound probe, forward or oblique endoscopic view, endoscopy brand), EUS procedure (indication, site, and visualization of the target lesion/ region, visualization of the pancreatic segments, distal gastrointestinal segment reached, AEs), EUS-TA (indication, technical success, EUS-TA outcome, AEs), and follow-up (surgical resection of the target lesion, patient's outcome, final diagnosis), were retrospectively collected.

\section{Definitions}

For the purpose of the study, we defined the target lesion/region as the focal pancreatic/bile duct lesion (if any) or the anatomic region to be visualized according to the EUS indication (e.g., the common bile duct [CBD] in case of suspected choledocholithiasis, the residual pancreatic segment in case of follow-up after pancreaticoduodenectomy).

AEs were defined according to the international lexicon [10]. Chart reviews or outpatient clinic records or telephone contact were used to assess AEs. Technical failure of TA was defined as inability to satisfactorily visualize the lesion or to introduce the needle inside the lesion; TA adequacy was defined as presence of a material representative of the target lesion sufficient for cytohistological evaluation [11]. Diagnostic performance of EUS-TA was evaluated in comparison with the final diagnosis: a) in operated patients, based on the surgical pathology; b) in non-operated patients, based on the conclusions of the diagnostic work-up (combined outcomes of tissue sampling and imaging studies), and confirmed by a compatible clinical disease course of at least 12 months [11].

\section{Endpoints}

The primary endpoint was represented by the percentage of cases with satisfactory visualization of the biliopancreatic target lesion/region according to the endosonographer stratified by the type of previous surgery. Visualization was considered satisfactory when endosonographers were able to visualize and to describe (i.e., to define as solid or cystic, echotexture, margins), to measure, and to define the anatomical site of the lesion, or when it was clearly stated in the EUS report that the target region (e.g., the CBD, the pancreatic head, body or tail) was completely explored.

Secondary endpoints were: 1 ) the percentage of visualization of the others pancreatic segments (other than the target site) according to the type of previous surgery; 2) the percentage of intraprocedural and postprocedural AEs; and 3) the performance (technical success, sensitivity, specificity, and accuracy) of EUS-TA among cases of solid pancreatic/distal bile duct lesions.

\section{Statistical analysis}

The study cohort was described by means ( \pm standard deviations) and medians (with range) for continuous data, and by proportions and percentages for categorical data. Chi-square and Fisher's exact tests (for cases with small expected frequen- 
cies $[<5])$ were used to analyze categorical variables. Student's $t$-test was applied to compare continuous data. Diagnostic performance of EUS-TA was calculated in an intention-to-diagnose analysis (i.e., including also cases of technical failures or inadequate samples that were considered as false negative).

Statistical significance was determined by $P<0.05$. All tests were two-tailed. Statistical analysis was performed with SPSS Statistics (Version 25.0, IBM Corp., Armonk, New York, United States).

\section{Results}

\section{Study population}

The initial search resulted in 318 procedures. After detailed evaluation, 76 were excluded: 61 were repeat procedures in the same patient, 10 underwent surgery not altering the upper gastrointestinal anatomy (four biliodigestive anastomoses, two gastric bandings, one distal pancreatectomy, two duodenoduodenostomies for duodenal atresia, and one Berger pancreatic head resection), and five did not have a biliopancreatic lesion (one lesion of the cardia, two liver lesions, and two submucosal gastric tumors). Therefore, our population finally consisted of 242 patients ( $\triangleright$ Fig. 1). Demographics and details regarding the type of surgery are summarized in $>$ Table 1.

Written informed consent was obtained before EUS in all cases. All procedures were performed by experienced endosonographers (at least 5 years of experience with more than 200 EUS/year). Deep sedation and conscious sedation were performed in 168 patients (69.4\%) and 74 patients (30.6\%), respectively. The linear-array oblique-view (EG-3870UTK, Pentax Medical, Tokyo, Japan or GF-UCT180/GF-UCT140-AL5, Olympus Medical Systems Corp., Tokyo, Japan) were the most commonly used echoendoscopes (206 procedures, $85.1 \%$ ), whereas a linear-array forward-viewer (TGF-UCT180 J, Olympus Medical Systems Corp., Tokyo, Japan) was used in 30 cases $(12.4 \%)$ in two centers. Finally, a radial-array oblique-view instrument (GF-UE260-AL5, Olympus Medical Systems Corp., Tokyo, Japan) was used in only six EUS procedures (2.5\%) in patients with pancreaticoduodenectomy.

Indications for biliopancreatic EUS were: suspected solid pancreatic lesions documented on cross-sectional imaging (computed tomography or magnetic resonance imaging) in 113 patients (46.7\%) (one patient had three lesions for a total of 115 lesions, mean size $25.1 \pm 13.3 \mathrm{~mm}$, range $8-70 \mathrm{~mm}$ ), suspected cystic pancreatic lesions in 44 (18.2\%, mean size $28.7 \pm$ $16.3 \mathrm{~mm}$, range $17-60 \mathrm{~mm})$, suspected choledocholithiasis in $25(10.3 \%)$, post-pancreatic resection follow-up in 15 (6.2\%), unexplained CBD dilation in 14 (5.8\%), main pancreatic duct dilation in $12(4.9 \%)$, suspected extrahepatic cholangiocarcinoma in five $(2.1 \%)$, chronic pancreatitis in 5 (2.1\%), pancreatic cancer screening in five $(2.1 \%)$, and idiopathic recurrent pancreatitis in four $(1.6 \%)$.
Patients underwent EUS after upper GI surgery $(n=318)$

Excluded $(n=76)$

- Surgery not altering the upper Gl anatomy $(n=10)$ :

- 4 bilio-digestive anastomoses

-2 gastric bandings

- 2 duodeno-duodenostomy

- 1 distal pancreatectomy

- 1 Berger pancreatic head resection

- Repeated procedures in the same patient $(n=61)$

- Not bilio-pancreatic lesions $(n=5)$ :

-2 lesions of the liver

- 2 submucosal gastric tumors

- 1 lesion of the cardia

Patients analyzed $(n=242)$

Fig. 1 Flowchart of the study.

- Table 1 Demographic and surgical features of study population.

\begin{tabular}{|c|c|}
\hline Feature & Value \\
\hline \multicolumn{2}{|l|}{$\operatorname{Sex} N(\%)$} \\
\hline - Males & 162 (66.9) \\
\hline - Females & $80(33.1)$ \\
\hline Mean age at EUS, years \pm SD & $66.4 \pm 12.5$ \\
\hline \multicolumn{2}{|l|}{ Surgical procedure, N (\%) } \\
\hline - Billroth II & $86(35.5)$ \\
\hline - Pancreaticoduodenectomy ${ }^{1}$ & $77(31.8)$ \\
\hline - Billroth I & $23(9.5)$ \\
\hline - Esophagectomy² & $19(7.9)$ \\
\hline - Total gastrectomy & $15(6.2)$ \\
\hline - Sleeve gastrectomy & $14(5.8)$ \\
\hline - Roux-en-Y gastric bypass & $8(3.3)$ \\
\hline \multicolumn{2}{|l|}{ Indication for surgery, N (\%) } \\
\hline - Malignancy & $102(42.1)$ \\
\hline - Peptic disease & $48(19.8)$ \\
\hline - Obesity & $15(6.2)$ \\
\hline - Other & $46(19)$ \\
\hline - Unknown & $31(12.8)$ \\
\hline \multicolumn{2}{|c|}{$\begin{array}{l}\text { EUS, endoscopic ultrasound; SD, standard deviation } \\
{ }^{1} \text { Including Whipple and pylorus-preserving pancreaticoduodenectomy. } \\
2 \text { Subtotal distal esophagectomy with gastric pull-up reconstruction. }\end{array}$} \\
\hline
\end{tabular}


- Table 2 Target lesion visualization stratified according to type of surgery.

\begin{tabular}{|c|c|c|c|}
\hline Type of surgery & Success, N (\%) & Failure, N (\%) & Site of unidentified lesion, (N) \\
\hline Roux-en-Y gastric bypass & $5 / 8(62.5)$ & $3 / 8(37.5)$ & Head $(3 / 3)$ \\
\hline Total gastrectomy & $10 / 15(66.7)$ & $5 / 15(33.3)^{1}$ & $\begin{array}{l}\text { Head }(3 / 4) \\
\text { Body }(1 / 3) \\
\text { Tail }(1 / 4)\end{array}$ \\
\hline Esophagectomy ${ }^{2}$ & $15 / 19(78.9)$ & $4 / 19(21.1)^{3}$ & $\begin{array}{l}\text { Head }(1 / 5) \\
\text { Tail }(3 / 5)\end{array}$ \\
\hline Billroth II & $69 / 86(80.2)$ & $17 / 86(19.8)$ & Head $(17 / 52)$ \\
\hline Pancreaticoduodenectomy ${ }^{4}$ & $71 / 77(92.2)$ & $6 / 77(7.8)$ & $\begin{array}{l}\text { Body }(3 / 21) \\
\text { Tail }(3 / 8)\end{array}$ \\
\hline Billroth I & $22 / 23(95.7)$ & $1 / 23(4.3)$ & Head $(1 / 1)$ \\
\hline Sleeve gastrectomy & $14 / 14(100)$ & $0 / 14(0)$ & - \\
\hline \multicolumn{4}{|c|}{$\begin{array}{l}{ }^{1} \text { In three cases none of the pancreatic segments could be visualized. } \\
{ }^{2} \text { Subtotal distal esophagectomy with gastric pull-up reconstruction. } \\
{ }^{3} \text { In three cases none of the pancreatic segments could be visualized. } \\
{ }^{4} \text { Including Whipple and pylorus-preserving pancreaticoduodenectomy. }\end{array}$} \\
\hline
\end{tabular}

\section{Target lesion/region and pancreatic segment visualization}

Overall, the target lesion/region was visualized in 206 patients (85.1\%) and failed to be imaged in 36 (14.9\%). The percentages of failed lesion visualization according to the type of surgery are summarized in $>$ Table 2 . Roux-en-Y gastric bypass and total gastrectomy were significantly associated with the worst target lesion visualization rate, which was achieved in only $62.5 \%$ and $66.7 \%$, respectively. Missed target lesions were localized in the head of the pancreas (HOP) in three of three (100\%) after Rouxen-Y gastric bypass and three of five $(60 \%)$ after total gastrectomy. Similarly, in patients with Billroth II resections, all $(\mathrm{N}=17)$ failed target visualizations concerns the HOP, whereas in cases of esophagectomies (subtotal esophagectomy with gastric pull-up reconstruction in all cases) the failures concerned all pancreatic segments in three of four cases (i.e., the pancreatic gland was not identified at all), and the HOP in one case. Conversely, there was no failed visualization in patients with sleeve gastrectomy, whereas in Billroth I and pancreaticoduodenectomy, the failure rates of target visualization were $4.3 \%$ and $7.8 \%$, respectively. No difference was observed in successful target lesion/region visualization rate using the frontal- or the oblique-view linear-array echoendoscope [25/30 cases (83.3\%) vs $174 / 216$ cases $(80.5 \%)$, respectively $(P=1)$ ].

Analysis of pancreatic segment visualization revealed that total gastrectomy significantly affected visualization of the HOP in only $6.7 \%$ of cases. Esophagectomy and total gastrectomy were the post-surgical altered anatomy reconstructions that most affected visualization of the body and the tail of the pancreas ( $82.4 \%$ and $71.4 \%$ rates of success, respectively). Sleeve gastrectomy did not affect pancreatic visualization regardless of the segment. The percentages of successful visualization of pancreatic segments according to the type of surgery are summarized in > Table 3 and depicted in > Fig. 2 .

\section{EUS-TA performance}

Among 113 patients with 115 solid pancreatic lesions (one patient with three lesions), EUS-TA was performed in 87 lesions. In six cases the lesion was not confirmed on EUS despite satisfactory visualization of the pancreatic region described in the EUS reports. Notably, these suspected lesions were not further reported on cross-sectional imaging during follow-up and were excluded from the analysis. In 18 lesions visualized by EUS, EUS-TA was not performed because it was not indicated for clinical reasons or a previous cytological diagnosis was available, while in three lesions, EUS was performed for fiducials marker placement and in one for lesion tattooing. Mean size of punctured lesions was $26.3 \pm 13.2 \mathrm{~mm}$ (range $8-70 \mathrm{~mm}$ ). Lesion visualization failed in fourteen of 87 cases $(16.1 \%)$, whereas it was impossible to puncture the lesion in five of 87 cases (5.7\%) (three lesions were judged to be too deep for puncture and in two cases, there was interposition of vessels). Therefore, the overall technical success rate was $78.2 \%$ (68/87 cases). Five of the 68 samples $(7.3 \%)$ were defined as inadequate for cytological interpretation. The final diagnosis was established on surgical pathology in 19 cases $(21.8 \%)$ and based on clinical follow-up in 68 cases (78.2\%). In an intention-to-diagnose analysis per lesion, there were 57 true positive, five true negative, 25 false negative, and no false positives. The sensitivity, specificity, and accuracy of EUS-TA were $69.5 \%$ (95\% Cl, 58.4-79.2), $100 \%$ (95\% Cl, 47.8-100), and $71.3 \%(95 \% \mathrm{Cl}, 60.6-80.5)$, respectively.

Finally, EUS-FNA was attempted in seventeen of 44 cases of cystic lesions and succeeded in twelve (70.6\%). Two of these cysts could not be imaged: one was located in the pancreatic body in a patient with esophagectomy and one in the pancreatic head in Billroth II. Three more technical failures were observed due to a very deep location of the lesions: two lesions located in the HOP in patients with Billroth II anatomy, and in 
- Table 3 Percentage of pancreatic segment visualization stratified according to type of surgery.

\begin{tabular}{|c|c|c|c|c|c|}
\hline \multirow[t]{2}{*}{ Type of surgery, (N) } & \multicolumn{3}{|c|}{ Pancreatic segment visualization, $\mathrm{N}$ (\%) } & \multirow{2}{*}{$\begin{array}{l}\text { Whole pancreas } \\
\text { visualization, } \mathrm{N}(\%)\end{array}$} & \multirow{2}{*}{$\begin{array}{l}\text { Whole pancreas failed } \\
\text { visualization, } \mathrm{N}(\%)\end{array}$} \\
\hline & Head/Uncinate & Neck/body & Tail & & \\
\hline Billroth II (86) & $\begin{array}{l}44 / 82(53.7) \\
4 \text { missing data }\end{array}$ & $\begin{array}{l}84 / 85(98.8) \\
1 \text { missing data }\end{array}$ & $\begin{array}{l}82 / 84(97.6) \\
2 \text { missing data }\end{array}$ & $\begin{array}{l}43 / 81(53.1) \\
5 \text { missing data }\end{array}$ & $\begin{array}{l}1 / 81(1.2) \\
5 \text { missing data }\end{array}$ \\
\hline $\begin{array}{l}\text { Pancreaticoduodenectomy }{ }^{1} \\
\text { (77) }\end{array}$ & NA & $\begin{array}{l}66 / 71 \text { (92.9) } \\
6 \text { missing data }\end{array}$ & $\begin{array}{l}67 / 70(95.7) \\
7 \text { missing data }\end{array}$ & $\begin{array}{l}65 / 70(92.9) \\
7 \text { missing data }\end{array}$ & $\begin{array}{l}3 / 70(4.3) \\
7 \text { missing data }\end{array}$ \\
\hline Billroth I (23) & $\begin{array}{l}19 / 21(90.5) \\
2 \text { missing data }\end{array}$ & $\begin{array}{l}19 / 19(100) \\
4 \text { missing data }\end{array}$ & $\begin{array}{l}18 / 18(100) \\
5 \text { missing data }\end{array}$ & $\begin{array}{l}16 / 18(88.9) \\
5 \text { missing data }\end{array}$ & $0(0)$ \\
\hline Esophagectomy² (19) & $\begin{array}{l}13 / 18(72.2) \\
1 \text { missing data }\end{array}$ & $\begin{array}{l}14 / 17(82.4) \\
2 \text { missing data }\end{array}$ & $\begin{array}{l}14 / 17(82.4) \\
2 \text { missing data }\end{array}$ & $\begin{array}{l}12 / 16(75) \\
2 \text { missing data }\end{array}$ & $\begin{array}{l}3 / 16(18.8) \\
2 \text { missing data }\end{array}$ \\
\hline Total gastrectomy (15) & $1 / 15(6.7 \%)$ & $\begin{array}{l}10 / 14(71.4) \\
1 \text { missing data }\end{array}$ & $\begin{array}{l}10 / 14(71.4) \\
1 \text { missing data }\end{array}$ & $\begin{array}{l}1 / 14(7.1) \\
1 \text { missing data }\end{array}$ & $\begin{array}{l}3 / 14(21.4) \\
1 \text { missing data }\end{array}$ \\
\hline Sleeve gastrectomy (14) & $14 / 14(100)$ & $14 / 14(100)$ & $14 / 14(100)$ & $14 / 14(100)$ & $0(0)$ \\
\hline Roux-en-Y gastric bypass ( 8 ) & $\begin{array}{l}4 / 7(57.1) \\
1 \text { missing data }\end{array}$ & $\begin{array}{l}6 / 6(100) \\
2 \text { missing data }\end{array}$ & $\begin{array}{l}6 / 6(100) \\
2 \text { missing data }\end{array}$ & $\begin{array}{l}4 / 5(80) \\
3 \text { missing data }\end{array}$ & $0(0)$ \\
\hline \multicolumn{6}{|c|}{$\begin{array}{l}\text { NA, not applicable. } \\
\text { Missing data refers to pancreatic segments visualization not stated in EUS reports. } \\
{ }^{1} \text { Including Whipple and pylorus-preserving pancreaticoduodenectomy. } \\
{ }^{2} \text { Subtotal distal esophagectomy with gastric pull-up reconstruction. }\end{array}$} \\
\hline
\end{tabular}

one lesion in the tail of the pancreas in a patient with sleeve gastrectomy. - Table 4 reviews the EUS-guided interventions and their outcomes in our study population.

\section{EUS-related adverse events}

Overall, we observed three AEs (1.2\%). Two were intraprocedural: one gastrointestinal bleeding after EUS-TA in a patient with Billroth I anatomy that was managed conservatively, and one cardiac arrest in a patient with esophagectomy that was successfully resuscitated. One post-procedural case of mild acute pancreatitis after EUS-TA in a patient with sleeve gastrectomy was also managed conservatively. Moreover, we observed one mucosal tear with exposure of the muscular layer at the level of the afferent limb in a patient with Billroth II anastomosis, which was managed endoscopically with the application of four clips, hospitalized for few days but without sequelae. Finally, according to the ASGE lexicon [10], we observed three "incidents": two cases of post-procedural abdominal pain not requiring further interventions or prolongation of scheduled observation and one intraprocedural bleed that did not cause a significant drop of hemoglobin or require additional medical intervention.

\section{Discussion}

In the current multicenter study, we aimed to evaluate the diagnostic performance and safety of biliopancreatic EUS in patients with surgically altered upper gastrointestinal anatomy. The primary outcome was identification of the target lesion or region that was satisfactorily imaged in $85 \%$ of patients and missed in $15 \%$. Therefore, post-surgical upper gastrointestinal anatomy significantly affects the diagnostic yield of biliopan- creatic EUS, which is known to have a negative predictive value close to $100 \%$ in normal upper gastrointestinal anatomy [12]. However, we found that identification of the target lesion is strictly related to the type of surgery and the location of the lesion. Indeed, total gastrectomy, Roux-en-Y gastric bypass, and Billroth II surgery significantly affect the overall target visualization for lesions located in the HOP. This is in agreement with previous literature. In a large single-center study published in 2010, patients with previous Billroth II surgery had a success rate for HOP visualization of $74 \%$ because of the difficult intubation of the afferent limb [5]. Similarly, in the same study, Roux-en-Y surgery negatively impacted pancreatic head visualization in the majority of patients [5]. Conversely, in our study, Billroth I and pancreaticoduodenectomy minimally impacted EUS performance, as previously reported [5]. Finally, unlike in past studies, we included 14 patients with sleeve gastrectomy, which is the most common bariatric surgery performed today and it is expected that endosonographers will have to deal with this condition more frequently in the future. Fortunately, this type of surgery does not seem to negatively impact biliopancreatic visualization, regardless of lesion location. However, in one case of a cystic lesion in a patient with sleeve gastrectomy, despite reportedly satisfactory visualization of the tail of the pancreas, EUS-FNA failed due to the very deep position of the lesion in the field of view.

In the current study, we also aimed to evaluate the rate of visualization of different pancreatic segments according to the type of surgery. The HOP was the most difficult region to image. In particular, we found that total gastrectomy is the surgically alteration that most negatively affects visualization of the pancreatic head, and in only one patient out of 15 who had undergone the surgery was visualization possible (approximately 


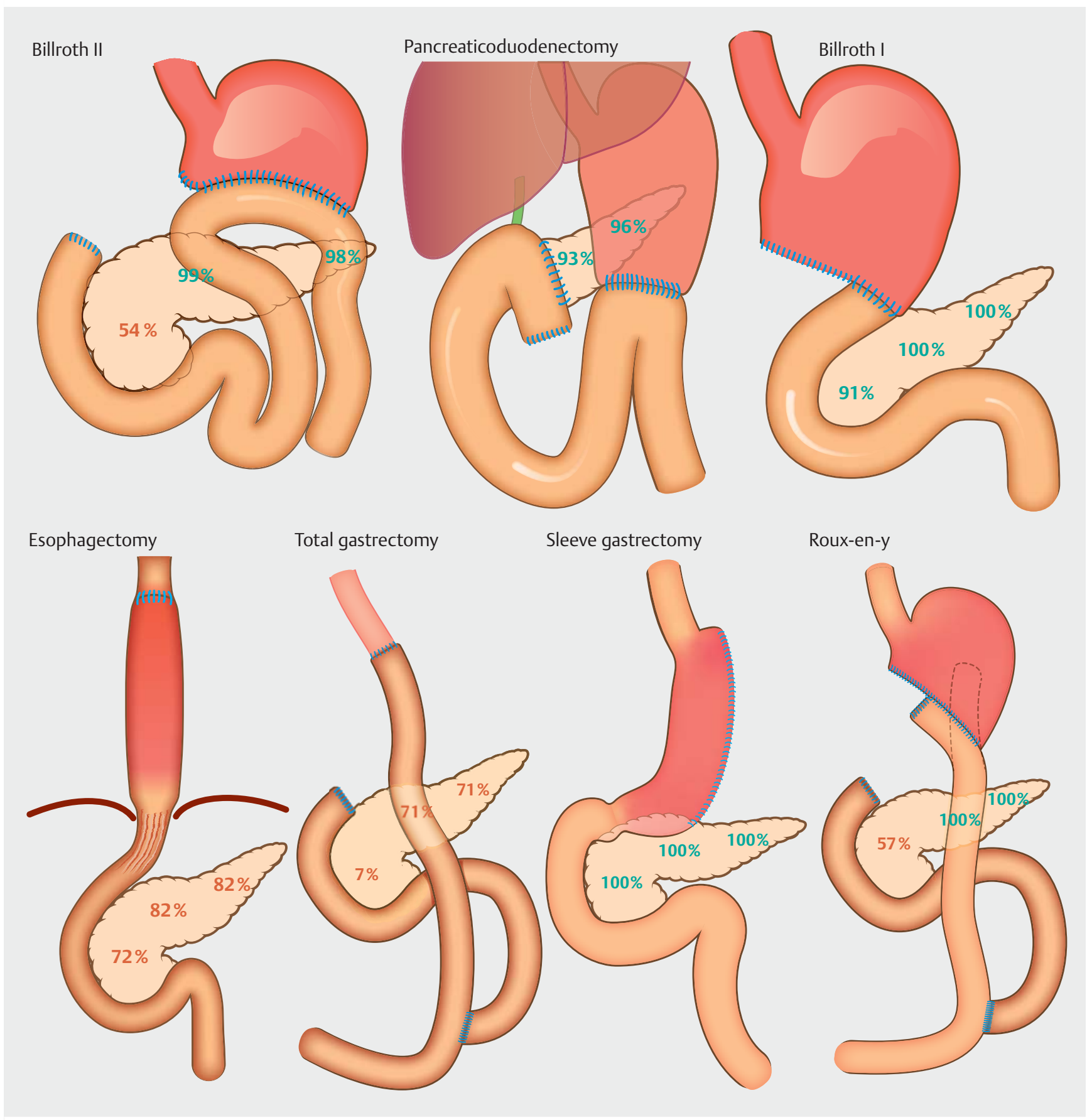

Fig. 2 Drawings illustrating the percentages of successful visualization of the pancreatic segments in different surgery anatomies.

$7 \%)$. As expected, the Billroth II and the Roux-en-Y gastric bypass postsurgical anatomies also significantly affected visualization of the pancreatic head. In our study, in such cases, imaging was possible in approximately $55 \%$, in substantial agreement with Wilson et al. [5], who reported successful visualization in $49 \%$ of cases, and with Topazian et al., who visualized the HOP in 10 out of 15 cases (66\%) with Billroth II anatomy. Interestingly, in our study, total gastrectomy and esophagectomy (in all cases subtotal distal esophagectomy with the stomach pulled-up into the thorax) had a significant impact on the visua- lization of the body and tail of the pancreas, which was obtained in only $70 \%$ and $80 \%$, respectively. Other types of postsurgical anatomy did not result in a reduced possibility of visualization of the head, body or tail of the pancreas.

We also evaluated EUS-TA performance for diagnosis of solid pancreatic lesions. Technical success was overall significantly lower than in normal anatomy. Indeed, in $16 \%$, the target lesion was impossible to image and in another $6 \%$ it could not be punctured. Moreover, $7 \%$ of samples were inadequate for cytopathological interpretation. The overall accuracy was approxi- 
-Table4 Endoscopic ultrasound-guided interventions and outcomes.

\begin{tabular}{|c|c|c|c|c|c|}
\hline Intervention & $\begin{array}{l}\text { Lesion size } \\
(\mathrm{mm}), \\
\text { mean } \pm \text { SD }\end{array}$ & $\begin{array}{l}\text { Lesions } \\
\text { site, (N) }\end{array}$ & Type of surgery, (N) & $\begin{array}{l}\text { Technical } \\
\text { success, N } \\
\text { (\%) }\end{array}$ & Reasons for failure, (N) \\
\hline $\begin{array}{l}\text { Tissue } \\
\text { acquisition } \\
\text { in SPLs (87) }\end{array}$ & $26.3 \pm 13.2$ & $\begin{array}{l}\text { Head (35) } \\
\text { Body (36) } \\
\text { Tail (16) }\end{array}$ & $\begin{array}{l}\text { Billroth II (36) } \\
\text { Pancreaticoduodenectomy }{ }^{1}(18) \\
\text { Billroth I (10) } \\
\text { Esophagectomy }{ }^{2}(8) \\
\text { Total gastrectomy ( } 8 \text { ) } \\
\text { Sleeve gastrectomy (4) } \\
\text { Roux-en-Y gastric bypass (3) }\end{array}$ & $68(78.2)$ & $\begin{array}{l}\text { Failed visualization (14) } \\
\text { Too deep to be punctured (5) }\end{array}$ \\
\hline $\begin{array}{l}\text { Cystic fluid } \\
\text { aspiration (17) }\end{array}$ & $32 \pm 11.4$ & $\begin{array}{l}\text { Head (7) } \\
\text { Body (8) } \\
\text { Tail (2) }\end{array}$ & $\begin{array}{l}\text { Billroth II (9) } \\
\text { Esophagectomy (2) } \\
\text { Billroth I ( } 2 \text { ) } \\
\text { Sleeve gastrectomy ( } 2 \text { ) } \\
\text { Total gastrectomy ( } 1 \text { ) } \\
\text { Roux-en-Y gastric bypass ( } 1 \text { ) }\end{array}$ & $12(70.6)$ & $\begin{array}{l}\text { Failed visualization ( } 2 \text { ) } \\
\text { Too deep to be punctured (3) }\end{array}$ \\
\hline $\begin{array}{l}\text { Fiducial place- } \\
\text { ment in SPLs (3) }\end{array}$ & $29.4 \pm 0.6$ & $\begin{array}{l}\text { Head (1) } \\
\text { Body (2) }\end{array}$ & $\begin{array}{l}\text { Esophagectomy }^{2}(1) \\
\text { Pancreaticoduodenectomy }{ }^{1}(2)\end{array}$ & $2(66.7)$ & Impossible to penetrate the lesion (1) \\
\hline $\begin{array}{l}\text { Lesion tattooing } \\
\text { of SPL (1) }\end{array}$ & 9 & Tail (1) & Billroth I (1) & $1(100)$ & NA \\
\hline
\end{tabular}

mately $70 \%$, which is significantly lower than that obtained in normal anatomy, where it is reported to exceed $90 \%$ [13]. Our results are slightly lower than those reported in a retrospective series of 25 patients where diagnostic accuracy was reported to be approximately $80 \%$ [14]. However, it should be emphasized that we calculated EUS-TA performance in an intention-to-diagnose analysis, considering as false negative the cases of failed lesion visualization.

In our study, the overall rate of AEs was approximately $1.2 \%$. In all these cases, however, there was an indication for TA $(2.6 \%$ in EUS-TA). In one patient (0.4\%) with Billroth II gastrectomy, there was a risk of scope perforation while passing through the afferent limb. Fortunately, only a mucosal tear was observed and managed by clipping endoscopically. If we consider this case a perforation, the risk of perforation seems slightly higher in our group compared with that of standard diagnostic EUS, where it is reported to be about $0.02 \%$ [15]. Therefore, we can state that overall, the procedure is safe, but a possible slightly higher risk of perforation compared with nonsurgical anatomy should be considered. However, when evaluating only patients who underwent EUS-FNA, the occurrence of perforation looks comparable $(0.63 \%$ in our study vs. $0.44 \%-0.86 \%$ in normal anatomy) [16]. Moreover, perforation during EUS in surgically altered anatomy seems less frequent compared with that reported during ERCP in Billroth II patients [17], possibly because the echoendoscope does not have to reach the papilla for HOP and distal bile duct visualization. Moreover, during ERCP, unlike with EUS, the duodenoscope is pushed and maneuvered into the afferent limb for several minutes to maintain a position stable enough to perform cannulation and sphincterotomy. Finally, the oblique endoscopic view of echoendoscopes may fa- cilitate afferent limb intubation better than do side-viewing duodenoscopes. Rates and severity of other AEs observed in our study (acute pancreatitis and bleeding) are similar to those reported during EUS in normal anatomy [14].

We are aware that our study has several limitations, mainly related to its retrospective design. First, most of the collected information comes from EUS reports or electronic charts that had not been filled for the purposes of the study. This approach most likely overestimates technical success rates and underestimates AEs rates. Indeed, it is impossible to know how many EUS procedures were not performed because of altered anatomy, leading to a potential selection bias toward procedures that were estimated to be possible and were performed. Moreover, minor AEs may not have been reported in medical files. Also, some data were missing regarding visualization of pancreatic segments other than the target region, and some interpretations may have been biased. A prospective study could overcome this limitation but would require a lengthy enrollment period to achieve a relevant sample size. Second, the study inclusion period was relatively large (10 years). In the last decade, several technological improvements to echoendoscopes and EUS-TA devices and techniques have been made, thus our results may not be fully reproducible in the future. Third, although this study was the largest on this topic, the number of patients evaluated was small for some surgery types. For example, we identified a few patients with Roux-en-Y gastric bypass, and we don't know how many Roux-en-Y patients did not undergo EUS because it was deemed too difficult. Fourth, given the retrospective and multicentric design of this study, a different approach to pancreatic exploration and could have been 
adopted by other endosonographers based on the surgical interventions that had been performed.

\section{Conclusion}

In conclusion, the diagnostic yield of biliopancreatic EUS in patients with prior surgically altered upper gastrointestinal anatomy is dependent on the location of the lesion and surgery type. Therefore, before considering EUS for pancreatic diseases in surgically altered anatomy, it is necessary to evaluate the pancreatic region to be studied according to the type of surgery.

\section{Acknowledgements}

The authors thank Giacomo Lazzari for the drawings for Fig. 2.

\section{Competing interests}

The authors declare that they have no conflict of interest.

\section{References}

[1] Chahal P, Baron TH, Topazian MD et al. Endoscopic retrograde cholangiopancreatography in post-Whipple patients. Endoscopy 2006; 38: $1241-1245$

[2] Hintze RE, Adler A, Veltzke W et al. Endoscopic access to the papilla of Vater for endoscopic retrograde cholangiopancreatography in patients with Billroth II or Roux-en-Y gastrojejunostomy. Endoscopy 1997; 29: 69-73

[3] Wright BE, Cass OW, Freeman ML. ERCP in patients with long-limb Roux-en-Y gastrojejunostomy and intact papilla. Gastrointest Endosc 2002; 56: 225-232

[4] Lee JH, Topazian M. Pancreatic endosonography after Billroth II gastrectomy. Endoscopy 2004; 36: 972-975

[5] Wilson JA, Hoffman B, Hawes RH et al. EUS in patients with surgically altered upper gastrointestinal anatomy. Gastrointest Endosc 2010; 72: $947-953$
[6] Fusaroli P, Ceroni L, Caletti G. Forward-view endoscopic ultrasound: a systematic review of diagnostic and therapeutic applications. Endosc Ultrasound 2013; 2: 64-70

[7] Kawakami H, Yoshimasa K. New curved linear echoendoscope for endoscopic ultrasonography-guided fine-needle aspiration in patients with Roux-en-Y reconstruction (with videos). Endosc Ultrasound 2018; 7: 128-129

[8] Itoi T, Itokawa F, Sofuni A et al. Endoscopic ultrasonography-guided fine needle aspiration biopsy in a patient with prior Billroth II gastrectomy. Dig Endosc 2011; 23: (Suppl. 01): 162-163

[9] Ban T, Kawakami H, Kubota Y et al. Endoscopic ultrasonographyguided fine-needle biopsy from the pancreatic head of a patient with Roux-en-Y reconstruction. Endoscopy 2018; 50: E202-E204

[10] Cotton PB, Eisen GM, Aabakken L et al. A lexicon for endoscopic adverse events: report of an ASGE workshop. Gastrointest Endosc 2010; 71: $446-454$

[11] Wani S, Muthusamy VR, McGrath CM et al. AGA White Paper: Optimizing Endoscopic Ultrasound-Guided Tissue Acquisition and Future Directions. Clin Gastroenterol Hepatol 2018; 16: 318-327

[12] Klapman JB, Chang KJ, Lee JG et al. Negative predictive value of endoscopic ultrasound in a large series of patients with a clinical suspicion of pancreatic cancer. Am J Gastroenterol 2005; 100: 26582661

[13] Armellini E, Manfrin E, Trisolini E et al. Histologic retrieval rate of a newly designed side-bevelled 20G needle for EUS-guided tissue acquisition of solid pancreatic lesions. United European Gastroenterol J 2019; 7: 96-104

[14] Tanaka K, Hayashi T, Utsunomiya R et al. Endoscopic ultrasoundguided fine needle aspiration for diagnosing pancreatic mass in patients with surgically altered upper gastrointestinal anatomy [Epub ahead of print]. Dig Endosc 2020: doi:10.1111/den.13625

[15] Jenssen C, Faiss S, Nürnberg D. Complications of endoscopic ultrasound and endoscopic ultrasound-guided interventions - results of a survey among German centers. Z Gastroenterol 2008; 46: 1177-1184

[16] Jenssen C, Alvarez-Sánchez MV, Napoléon B et al. Diagnostic endoscopic ultrasonography: Assessment of safety and prevention of complications. World J Gastroenterol 2012; 18: 4659-4676

[17] Bove V, Tringali A, Familiari P et al. ERCP in patients with prior Billroth II gastrectomy: report of 30 years' experience. Endoscopy 2015; 47: 611-616 